American J. of Engineering and Applied Sciences 2 (2): 416-420, 2009

ISSN 1941-7020

(C) 2009 Science Publications

\title{
Analysis of the Tunnel Boring Machine Advancement on the Bologna-Florence Railway Link
}

\author{
M. Cardu, P. Oreste and T. Cicala \\ Department of Land, Environment and Geotechnology Engineering, \\ Polytectnic University of Turin, Corso Duca Degli Abruzzi 24, Torino, Italy
}

\begin{abstract}
Problem statement: The high-velocity railway link between Bologna and Firenze (Italy) is today under construction and several tunnels have to be excavated for this purpose, some of these using TBMs. A small diameter tunnel, named Cunicolo ginori, was realized by TBM parallel to a large railway tunnel (Vaglia), at the distance of only $35 \mathrm{~m}$. Approach: The Vaglia tunnel had been excavated by conventional methods and provided, thanks to a detailed survey and a systematic geotechnical monitoring (rock quality evaluation and convergence measurements) the characterization data of the crossed rock mass; moreover the TBM performance data in Cunicolo ginori were continuously monitored. A tunnel stretch, $587 \mathrm{~m}$ long, was recorded and the analysis of the data from both surveys allowed to correlate the geomechanical parameters of the rock-mass to the TBM performances (net advancement rate, thrust, specific energy). Results: Based on this large amount of data a new system to predict the net TBM advancement rate for a tunnel in rock masses of known geological and geomechanical characteristics was then developed. Also the Utilization Coefficient (CU) can be correlated to the rock quality Indices: The net advance rate and the utilization coefficient provide a mean to foresee the gross advancement rate and to evaluate the suitability of a machine for the excavation of a tunnel. Conclusion: In this study, an analysis had been carried out on about $587 \mathrm{~m}$ of a service tunnel, excavated by a TBM in a flysch formation.
\end{abstract}

Key words: Tunnel Boring Machine (TBM), net advancement rate, Utilization Coefficient (CU)

\section{INTRODUCTION}

Amongst the main railways connections along the Italian Peninsula, the Bologna-Firenze link belongs to the Milano-Napoli connection and has a long history: From the first attempts of planning a railway in the 19th Century to the present railway connection (the so called Direttissima), to the railway now under construction for the high speed trains (TAV).

The new link Bologna-Firenze, planned in 1992, is $78 \mathrm{~km}$ long, 73 of whose are placed in tunnels, with a slope of $1.2 \%$ and an altitude of $414 \mathrm{~m}$ above sea level.

One of the longest tunnels of this connection is Vaglia tunnel, around $18.5 \mathrm{~km}$ long. For safety reasons, a service tunnel (called Cunicolo ginori) has been driven, parallel to Vaglia, at the place of Adits for the passengers evacuation. The service tunnel was linked with the main tunnel by means of 20 by-pass, spaced $250 \mathrm{~m}$.

The characteristics of the railway line ( curvature radius $5450 \mathrm{~m}$, platform width $13.6 \mathrm{~m}$, distance between rails $5 \mathrm{~m}$, maximum grade $1.2 \%$ ), involved to adopt for the Vaglia tunnel a cross section of $82 \mathrm{~m}^{2}$.
For the service tunnel, essentially conceived for safety and aid uses, a pedestrian width of almost $2.5 \mathrm{~m}$ and an internal cross section of around $24 \mathrm{~m}^{2}$ were chosen. The lack of time to complete the works brought to the choice of a TBM to realize the service tunnel, running parallel to Vaglia at a distance of $35 \mathrm{~m}$, for a total length of $6.5 \mathrm{~km}$ (Fig. 1). A short stretch (around $1.5 \mathrm{~km}$ ) of the service tunnel is placed in an urbanized area, with clayey soil as overburden: therefore, this section was excavated by means of conventional methods (road-header and D and B). From the portal, a stretch of the service tunnel, around $1588 \mathrm{~m}$ long, runs downwards with a slope of $10.8 \%$; the final section, $1170 \mathrm{~m}$ long, rises with the same grade. The overburden of the two tunnels was comprised between 167 and $364 \mathrm{~m}$.

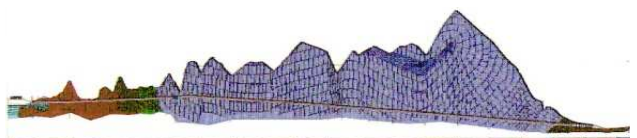

Fig. 1: Layout of the Vaglia tunnel

Corresponding Author: M. Cardu, Department of Land, Environment and Geotechnology Engineering, Polytectnic University of Turin, Corso Duca Degli Abruzzi 24, Torino, Italy 
The Vaglia tunnel has been excavated by roadheaders or D and $\mathrm{B}$, depending on the type of the crossed rock mass, starting from the two portals and from windows drifts. During the works, the Vaglia tunnel progression has been of around $3.8 \mathrm{~m} \mathrm{day}^{-1}$, while the advancement rate of the TBM in the service tunnel was around $20 \mathrm{~m} \mathrm{day}^{-1}$.

In an area whose length was around $587 \mathrm{~m}$, the characteristics of the rock mass interesting the two tunnels were investigated by means of surveys and the TBM performances were also monitored.

The correlations between the TBM performances (in the service tunnel) and the rock mass properties (in the Vaglia tunnel) have been, then, the base of the study presented in this research.

\section{MATERIALS AND METHODS}

Geology of the area: The stretch of the railway connection here examined is oriented NNE-SSW. The small river Cerretana crosses the axis of the tunnels in almost orthogonal direction and its tributaries form the hydrographical network of the zone.

The rock mass crossed by the two tunnels is part of a complex formation (called Monte morello), where the following lithotypes are present:

- Calcareous mudstones: Grey colored, with hard and compact texture

- Calcarenites and calcareous sandstone: Light grey color, with granular texture and homogeneous structure

- Grey and brown marls: Soft and sometimes hard consistency, with compact and homogeneous texture

- Black-dark shales: Soft and very soft consistency, sometimes laminated structure, with thin lens of spathic calcite

- Intermediary beds are formed by marly limestones, argillaceous marls and marl clays

From Lugeon tests in drill-holes, a permeability between $10^{-7}$ and $10^{-8} \mathrm{~m} \mathrm{sec}^{-1}$ has been determined.

\section{Geomechanical characterization:}

Laboratory tests: On behalf of the tunnel contractor, laboratory and in situ rock characterization were carried out. The average results of the laboratory tests are shown in Table 1.

In situ tests: Direct in situ investigations were carried out to evaluate the natural stress of the rock mass, by means of hydraulic fracture tests in vertical bore-holes at the depth of 200,300 and $500 \mathrm{~m}$ respectively.
Table 1: Laboratory characteristics of the rock types

\begin{tabular}{llllllll}
\hline Lithotype & $\begin{array}{l}\text { UCS } \\
(\mathrm{MPa})\end{array}$ & $\begin{array}{l}\mathrm{TS} \\
(\mathrm{MPa})\end{array}$ & $\begin{array}{l}\mathrm{E} \\
(\mathrm{MPa})\end{array}$ & $\begin{array}{l}\rho \\
\mathrm{g} \mathrm{cm}^{-3}\end{array}$ & $v$ & $\begin{array}{l}\mathrm{v} \\
\left(\mathrm{m} \mathrm{sec}^{-1}\right)\end{array}$ & $\begin{array}{l}\mathrm{WC} \\
(\%)\end{array}$ \\
\hline $\begin{array}{l}\text { Marly } \\
\text { limestone }\end{array}$ & 105 & 8.7 & 32500 & 2.63 & 0.21 & 4218 & 0.77 \\
Limestone & 104 & 6.7 & 41229 & 2.63 & 0.23 & 4974 & 0.90 \\
Marl & 99 & 5.5 & 26460 & 2.62 & 0.21 & 3989 & 1.25 \\
Sandstone & 58 & - & 6797 & 2.68 & - & & $0.9-1$ \\
\hline
\end{tabular}

UCS: Uniaxial Compressive Strength; TS: Tensile Strength; E: Secant Young modulus; $\rho$ : Specific mass; $v$ : Poisson ratio; v: p-wave velocity; WC: Water Content

Table 2: Orientation and spacing of the principal discontinuities

\begin{tabular}{lll}
\hline & Orientation (dip/dip dir.) & Spacing $(\mathrm{cm})$ \\
\hline Strata-beds & $23 / 321$ & $40-80$ \\
K1 & $73 / 170$ & $20-40$ \\
K2 & $83 / 093$ & $20-40$ \\
\hline
\end{tabular}

In particular, the vertical natural stresses measured was in a very small displacement respect to the theoretical values deduced from $\sigma_{\mathrm{v}}=\gamma \mathrm{H}$, where $\mathrm{H}$ is the depth, $\gamma$ the specific weight and $\sigma_{v}$ the vertical stress. Average values are placed between 7.5 and $12.7 \mathrm{MPa}$.

Geo-structural surveys: Several geo-structural surveys were carried out to classify the rock mass, both on appropriate superficial sites and in bore-holes, both with camera measurements and by means of fracture logs on drill cores. They allowed identifying the interbeds of the strata as the main element of the discontinuity of the rock mass. The statistical analysis of the joint orientation highlighted the presence, beyond the rock stratification, of two sets of sub-vertical fractures (K1 and K2) and of another set (K3) of lower inclination. Table 2 shows the main discontinuity characteristics of the rock mass along the tunnel layout, in three survey stations.

The tunnel layout runs almost parallel to the strata beds, whose orientation is sub-horizontal; their thickness varies from some centimeters to some decimeters, the discontinuities being, frequently, opened and filled with clay or spatic calcite. The spacing between discontinuities, often with vertical orientation, is greater than the thickness of strata beds. The available data show that the discontinuities crossed by the tunnels should, almost locally, weaken the rock mass. The ratings, according to the Bieniawski and Barton rock mass classifications, were also found.

Geotechnical characteristics of the rock mass show, therefore, a good workability, with local medium hardness elements, as grey sound limestone.

TBM characteristics: To face the stability problems during the excavation of the Cunicolo ginori, a double shielded TBM has been chosen. The main characteristics of the machine are shown in Table 3. 
Table 3: Technical data of the TBM TB 630 E/TS used to excavate Cunicolo ginori

\begin{tabular}{ll}
\hline Boring diameter & $6.3 \mathrm{~m} \mathrm{[6.27} \mathrm{(worn} \mathrm{disks)]}$ \\
Standard oversize & $55 \mathrm{~mm}[40 \mathrm{~mm}$ (worn disks)] \\
Disk diameter & $432 \mathrm{~mm}$ \\
Number of disks & 46 \\
Disk spacing & $80 \mathrm{~mm}$ \\
Power on the cutter-head & $7 \times 280 \mathrm{~kW}$ \\
Rotation speed & $0-7.3 \mathrm{rpm}$ \\
Torque & $2560 \mathrm{kNm}$ \\
Break out torque & $5500 \mathrm{kNm}$ \\
Stroke & $1.4 \mathrm{~m}$ \\
Front shield: Maximum thrust & $25330 \mathrm{kN}$ (400 bar on the \\
& cylinders) \\
Front shield: Grippers max. thrust & $57650 \mathrm{kN}$ \\
Front shield: Max. pressure & $4.7 \mathrm{MPa}$ \\
on the tunnel wall & \\
Back shield: Thrust & $34400 \mathrm{kN}$ \\
Installed total power & $3000 \mathrm{~kW}$ \\
Transformers & $2 \times 1750 \mathrm{kVA}$ \\
\hline
\end{tabular}

In the case of rock squeezing, the boring diameter could be increased by means of three enlarging disks, to create a tunnel oversize. Moreover, the rotational speed could be modified by Variable Frequency Drive (VFD) system, that makes easier the break out of the cutterhead in the case of face instability.

The TBM was furthermore supplied with an erector, whose carrying capacity was $40 \mathrm{kN}$, to place the segment of the lining on the tunnel walls. The lining, composed by $25 \mathrm{~cm}$ thick rings of six segments as well as the key, was placed at 11-13 $\mathrm{m}$ distance from the machine cutterhead, following the TBM advancement. An injection of pea-gravel filled the voids between the tunnel wall and the external surface of the segments.

The muck was carried away by means of a conveyor belt, having a capacity of around $700 \mathrm{~m}^{3} \mathrm{~h}^{-1}$, placed behind the machine back-up.

The TBM worked 5 days per week on three shifts. The remaining two days were used for the machine maintenance and disk replacements.

\section{RESULTS AND DISCUSSION}

Deduction of possible relationships between the rock mass characteristics and the TBM performance parameters.

TBM performance parameters: Amongst the machine performance parameters that were recorded on magnetic support, an analysis was carried out to evaluate the following parameters ${ }^{[2,3]}$ : Thrust per disk, net progression speed (from which the penetration per revolution was deducted), excavation specific Energy $\left(\mathrm{E}_{\mathrm{s}}\right)$ and utilization coefficient. Figure 2 shows the first three main above said parameters (averaged on daily values) Vs chain-age.

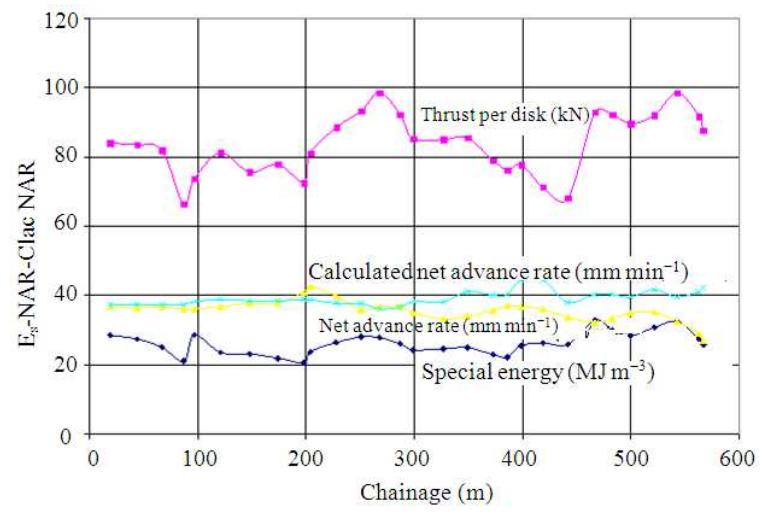

Fig. 2: Trend of the specific Energy $\left(E_{s}\right)$, Net advance rate $(\mathrm{v})$, calculated net advance rate and thrust Vs chain-age, in the analyzed stretch of the Cunicolo ginori

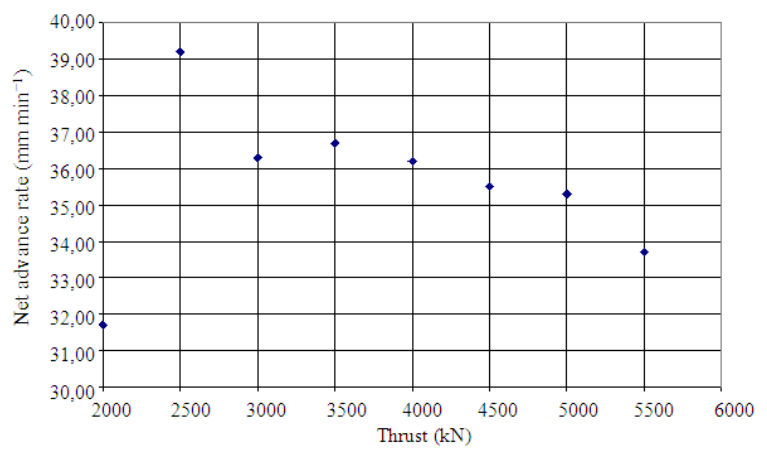

Fig. 3: Net advance rate Vs applied thrust on the cutter head

The TBM parameters (progression speed, excavation specific energy and so on) were also averaged on the following cutter-head thrust intervals: $<2000$; 2000-2500; 2500-3000; 3000-3500; 3500-4000; 4000-4500; 4500-5000; >5000 kN.

Penetration per revolution: Penetration per revolution is one of the most important parameters often used to predict TBM performances. It depends on the applied thrust and on the properties of the rock mass and intact rock. In Fig. 3 the net progression speed is plotted against the applied thrust on the cutter head. Though being obvious, from a theoretical point of view, a relationship between these two parameters, it seems that this is not evident in the examined case. The explication should be due to the fact that the TBM operator has limited the thrust to a value just enough to obtain an optimal penetration related to the estimated (by himself) rock mass stability conditions. 
An analysis was also made to compare the actual penetration values of the TBM to some predictive laws. In particular, a law has been taken into account ${ }^{[2]}$, in which both the Uniaxial Compressive Strength (UCS) of the rock and a quality index of the rock mass ${ }^{[4]}$ were considered:

$\mathrm{p}=40 \cdot \sigma_{\mathrm{c}}^{-0.437}-0,047 \cdot \mathrm{RSR}+3.15$

Where:

RSR = The Wickham rating of the rock mass

$\sigma_{\mathrm{c}}(\mathrm{MPa})=$ The UCS of the intact rock

$\mathrm{p}=$ The penetration per round value $(\mathrm{mm}$ per round)

Therefore, the Net Advance Rate (NAR, $\mathrm{mm} \mathrm{min}^{-1}$ ) can be evaluated by: NAR $=p \times n$, where $n$ is the number of cutter-head revolutions per min. Taking into account $\sigma_{\mathrm{c}}=100 \mathrm{MPa}$ as mean value of the rock mass UCS and having evaluated the RSR rating from $\mathrm{RMR}^{[1]}$ by means of the relationship: $\mathrm{RSR}=0.77 \mathrm{RMR}+12.4$, the predicted values of the TBM penetration can be deduced.

Figure 2 shows the trend of the actual and calculated (by Eq. 1) values of the TBM net advancement rates. The difference between the calculated and actual penetration values varies from 2$25 \%$, with an average of $9 \%$.

Excavation specific energy: The amount of cutterhead power required to bore is a function of the rock mass conditions and of some machine characteristics, as diameter and number of disk tools, diameter of the cutter-head and penetration. It is known that, as the rock strength increases, the tangential force on each cutter also increases, if the same level of penetration is maintained.

To bore jointed or fissured rocks, the power required is sometimes greater than that necessary to bore un-jointed rocks, because the loosened blocks produce higher rolling forces and then higher cutterhead torques are necessary.

An index that comprises both the power (and then the torque) and the production is the excavation specific energy.

The importance of the evaluation of the excavation specific energy goes back to the Sixties, when the machines began to be studied and analyzed by a theoretic and practical points of view ${ }^{[3]}$. The specific energy can be expressed by two terms, the first one related to the cutter-head rotation, the second one to the advancement. It is easily understandable that the second term is negligible respect to the first one. The specific energy is then simply calculated as the ratio between the cutter-head power and the excavated volume per unity time, through the relationship:

$\mathrm{E}_{\mathrm{s}}=(\mathrm{C} \cdot \omega) /(\mathrm{v} \cdot \mathrm{A})$

Where:

$\mathrm{C}=$ The cutter-head torque

$\omega=$ The rotation speed of the cutter-head

$\mathrm{v}=$ The net advance rate

$\mathrm{A}=$ The cross section of the tunnel

From Eq. 2 it is also possible to observe that, being torque and $\omega$ constant, the specific energy is inversely correlated to the advance rate, as was statistically observed in several TBM works.

In the case of the Cunicolo ginori, the relationship between specific Energy $\left(E_{\mathrm{s}}\right)$ and cutter-head thrust is shown in Fig. 4. A linear relationship can be then asserted between the two parameters, as implicit in the fact that the cutter-head torque increases with the tangential (and then with the normal) thrust.

Figure 5 shows a reasonably linear relationship between the applied thrust and the Rock Mass Rating, though being the correlation coefficient smaller than the statistical value $(0.612$ Vs 0.669 , with a confidence level of $90 \%)$. Also for $\mathrm{v}$ and $\mathrm{E}_{\mathrm{s}}$ can be found a linear relationship with RMR (Fig. 6 and 7). In particular, it results to be very interesting the possibility of estimating $E_{\mathrm{s}}$ when the RMR index for the rock mass is known. Once $E_{\mathrm{s}}$ is determined, one can choose the suitable machine or can obtain the net advancement rate for the chosen machine.

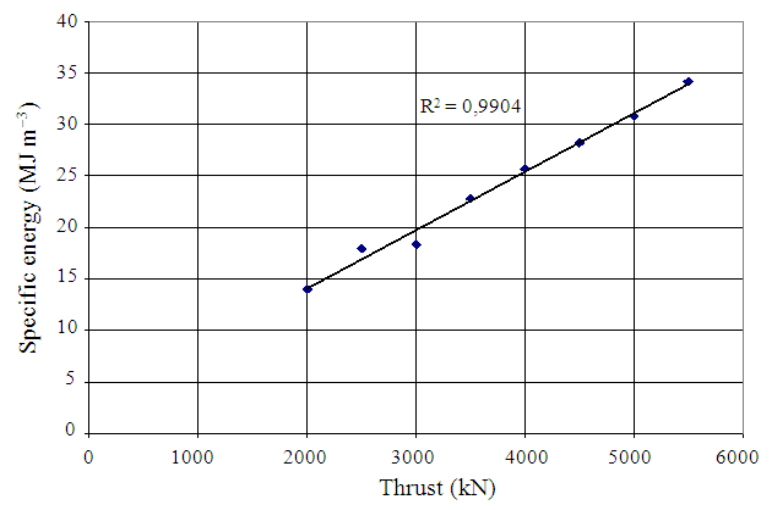

Fig. 4: Excavation specific energy Vs Thrust applied to the cutter-head 


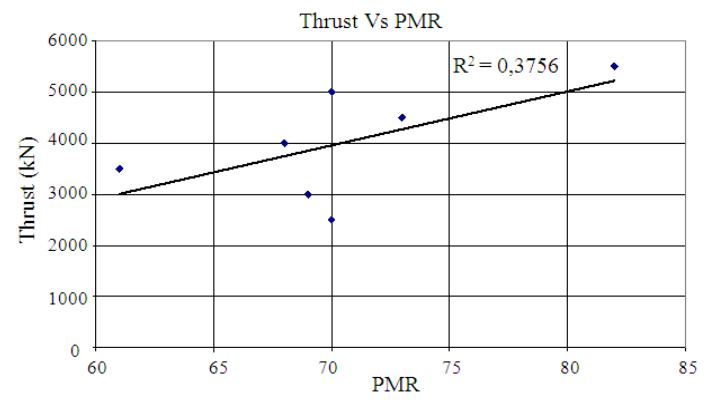

Fig. 5: Applied thrust Vs RMR

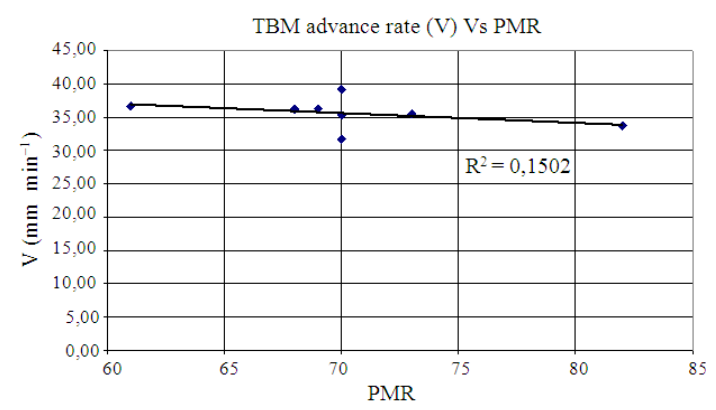

Fig. 6: Net advance rate (v) Vs RMR

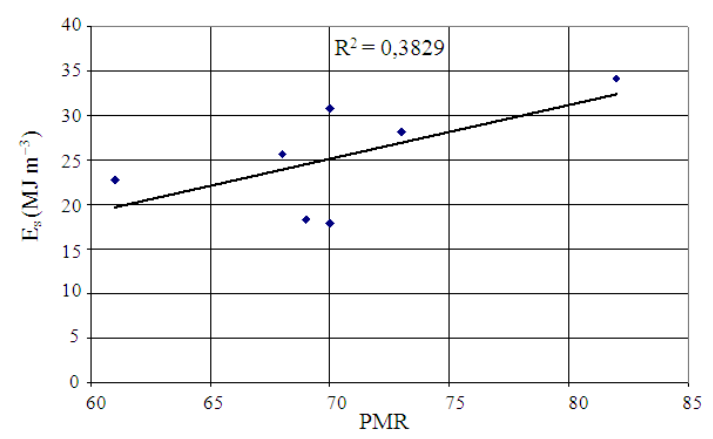

Fig. 7: Trend of the specific energy Vs RMR

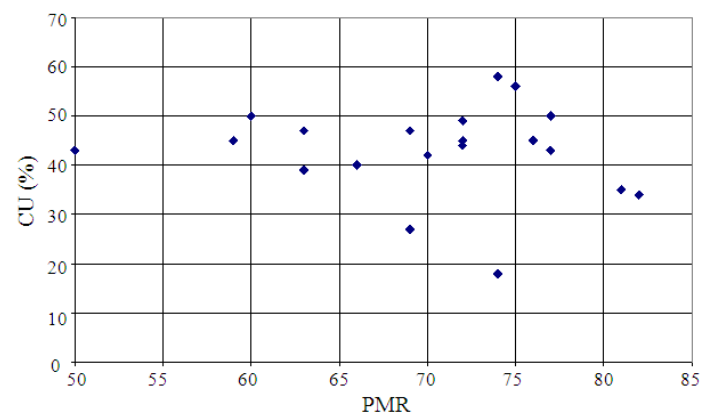

Fig. 8: Utilisation coefficient Vs RMR

Finally, the trend of Utilisation Coefficient (CU) Vs RMR (Fig. 8) shows that highest values have been found in the RMR range 72-75 and minimum values for RMR $<60$ and between 80 and 82 . This trend confirms what is asserted in several cases of works by TBM, that is the difficulty to work in conditions of tunnels instability, or, on the contrary, in hard rock without a pronounced set of discontinuities.

\section{CONCLUSION}

In this study, an analysis has been carried out on about $587 \mathrm{~m}$ of a service tunnel, excavated by a TBM in a flysch formation. Some relationships has been highlighted between the excavation specific energy, net advance rate, thrust on the cutter-head and the Rock Mass Rating. A TBM performance predictive law has been also applied verifying a scarce gap between the predicted and actual values of the net advance rate. The found relationship between excavation specific energy and RMR can help the choose of the TBM for a specific tunnel or the estimation of the net advance rate using a specific machine.

\section{REFERENCES}

1. Bieniawski, Z.T., 1989. Engineering Rock Mass Classification. John Wiley and Sons, New York, USA., ISBN: 0-471-60172-1.

2. Innaurato, N. and S. Pelizza, 1968. Judgmental analysis of tunneler performance. Boll. Ass. Min. Subalpina, 5: 345-398.

3. Innaurato, N., R. Mancini, E. Rondena and A. Zaninetti, 1990. An application of rock classification to the excavation using TBMs. Boll. Ass. Min. Subalpina, 27: 73-98.

4. Teale, R., 1965. The concept of specific energy in rock drilling. Int. J. Rock Mech. Min. Sic., 2: 57-73.

http://72.14.235.132/search?q=cache:VKIXdDCE5 2oJ:www.spegcs.org/attachments/studygroups/3/20 07_Drlg\%2520Sym_Optimizing\%2520Bit\%2520P erformance.ppt+The+concept+of+specific+energy + in+rock+drilling \&cd=1\&hl=en\&ct=clnk\&gl=pk

5. Wickham et al., 1974. Ground support prediction model. RSR concept. NTIS. Report, S. Francisco. http://jacobssf.com/art_wickman\%20rock\%20struc t.html 